\title{
The Use Of Social Networking Websites As A Recruiting Tool For Employers
}

\author{
Jamie Vicknair, Southeastern Louisiana University, USA \\ Dalia Elkersh, Southeastern Louisiana University, USA \\ Katie Yancey, Southeastern Louisiana University, USA \\ Michael C. Budden, Southeastern Louisiana University, USA
}

\begin{abstract}
The use of online social networking is a commonplace occurrence. A recent trend is for employers and recruiters to utilize social networking sites to screen candidates as part of the hiring process. This study examines student attitudes and awareness of these practices.
\end{abstract}

Keywords: Recruiting, Social Networking, Social Recruiting, Human Resources

\section{INTRODUCTION}

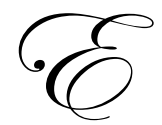

mployers are increasingly turning to social networking sites as a tool for screening job applicants. According to a survey conducted by Careerbuilder.com (2010), 45\% of companies in 2009 used social networking websites as a screening tool for job applicants, a number twice as high as the year before. This statistic indicates the popularity of using these sites as a human resource tool. The use of social networking websites by individuals is a widespread phenomena. The website Facebook.com is currently home to over 400 million users with half of those logging into their account at least once every day (Facebook.com 2010).

The term "social recruiting" is a buzz phrase used throughout the HR world, which can be defined as "harnessing the evolution of Web 2.0 technologies and social media tools to communicate, engage, inform, and recruit our future talent" ( Jacobs 2009). The use of such social networking websites allows recruiters to connect to a broad array of talented and capable candidates in niche communities (Jacobs, 2009). Reviewing candidates' social networking profiles can be a helpful tool for recruiters looking to hire a candidate. According to an article from HR Focus, a candidates' social networking profile helped a candidate get a job because their profile demonstrated they were well-rounded, creative, had received awards and accolades, and would be a good fit. However, reasons candidates did not receive job offers based on their social networking profiles included the demonstration of poor communication skills, drinking/drug use content, bad mouthing of previous employers/co-workers/clients, and/or posting provocative/inappropriate photographs (HR Focus 2009).

The use of social networking sites provides socializing outlets and allows users to use their "profile" as a means of self expression and creates a person's social sphere (Hoy and Milne 2010). The Pew Research Center released a study stating three-quarters of all millennials (those between the ages of 18-29) have created a profile on a social networking site as a means of self expression (Pew Research Center, 2010). According to Budden, Anthony, Budden, \& Jones (2007), internet usage for college students has increased and social networking online has been growing at an accelerating pace. A recent study indicated that participants spent an average of 6.22 hours per week using Facebook and MySpace (Budden, et.al 2007). Many students perceive their profile to be private and only available to be viewed with their consent. Students' unawareness of the unreliable security of social networking profiles can result in negative consequences. Decker (2006) believes users have a relaxed attitude toward personal privacy. For instance, student was kicked out of his school's honor society because he created a Facebook page that criticized his school (FOXNews.com 2010). Certain information posted on social networking profiles can have negative implications on college students looking to enter the job market. According to Karl \& Peluchette, job offers have been rescinded and internships terminated on the basis of messages and pictures posted on Facebook. One journal notes that using online social networking sites as a tool for recruitment may not provide a true or 
accurate portrayal of a candidate's personal life or how they may perform on the job (Oleniczak, Pike, Mishra, and Mishra 2010).

\section{OBJECTIVES}

An earlier study conducted by Janelle Harrison (2008) investigated student awareness of employer use of social networking websites as a candidate screening tool. Following on the heels of that study, objective for this study were developed:

- Are students aware that employer's have the ability to find information through social networking websites?

- Have students posted information on their social networking profiles they would not want an employer/recruiter to see?

- $\quad$ Do students approve of employers checking social networking profiles as part of the screening effort?

- $\quad$ Are students concerned about the legitimacy of their social networking profile privacy?

- Would students provide potential employees with their social networking profile passwords in order to be considered for a job?

\section{METHODOLOGY}

A voluntary convenience survey was created to explore research objectives. The questionnaire consisted of nine questions pertaining to the primary objective and four questions designated to respondent demographics. Four open-ended questions encouraged explanations to the nature responses. The survey was emailed and handdistributed to a random sample of students from all classifications and majors at a state university. Hard copy surveys were distributed to ten classes and upon completion were manually entered by researchers using the online survey. Data from both forms of distribution was recorded using the GoogleDocs application. After the data was combined, it was analyzed using SPSS. The response was 289 students consisting of $39.6 \%$ male respondents and $60.4 \%$ female respondents. Of the respondents, 32\% were freshman, 9.5\% sophomores, $13 \%$ juniors, $25.7 \%$ seniors, and $19.7 \%$ graduate students.

\section{RESEARCH STATISTICS}

\section{Respondents Using Social Networking Websites}

The use of online social networking is a daily occurrence on most college campuses. In order to determine the demographics for the research a survey was distributed regarding the gender, classification, employment status, and organizational involvement of the respondents. Research regarding use of social networking indicated that of the 289 respondents' $91.7 \%$ currently use an online social networking site such as Facebook, Twitter, Myspace, or LinkedIn. Of those users $37 \%$ reported are male, and $62 \%$ are female. There was little variance in usage of online social networking among respondents who were full-time employees, part time employees, or unemployed and the majority of these did claim to use a form of social networking. Of respondents seeking employment, $33 \%$ admitted to currently using some form of online social networking. Respondents belonging to an on-campus organization made up $29 \%$ of online social networking users.

\section{Are students aware that employer's may have the ability to gather recruiting information through social networking websites?}

The survey inquired as to whether respondents were aware that employers or recruiters could view their social networking profile even if the account settings were set to private, simply by entering a specific search string into many search engines. The survey found $49.3 \%$ of respondents were aware, while $50.7 \%$ of respondents were not aware that employers or recruiters could view their social networking profile. Harrison's (2008) study revealed the majority $(63.3 \%)$ of respondents were not aware of this fact. Of the respondents involved in on-campus organizations $58 \%$ believed employers could view their social networking profiles. Of those respondents not involved in on-campus organizations, 55\% believed employers could not view their social networking profiles. 
According to "Managing Accounts Payable", recruiters in companies feel entitled to view a candidate's social networking profile. One quarter of 254 employers surveyed admitted to reviewing an applicant's social networking profile prior to making a job offer (Harrison, 2008, p.11).

Respondents were asked how often they believed employers viewed social networking profiles. The largest response $(45.3 \%)$ indicated they believe employers and recruiters look at job candidates social networking profiles all of the time. These results are in contrast to the findings of Harrison's (2008) study where only $15.6 \%$ of respondents believed employers did this. Perhaps students are becoming increasingly aware of this potential. Respondents from all educational classifications indicated they believed employers looked at social networking profiles all of the time or some of the time. A majority (65\%) of respondents claiming not to be seeking employment indicated they believed employers look at candidates social networking profiles all of the time, while only $31 \%$ of those reporting seeking employment believed the same. Many college students believe their social networking profiles are private but are actually being viewed by potential employers (Budden \& Budden,2008).

\section{Do students place or have they ever placed information in social networking profiles they would not want employers/recruiters to see?}

According to The HR Specialist (2010), the top three reasons employers reject candidates after online screening are because they posted provocative or inappropriate photos or information, they posted content regarding use of drinking or drugs, and because they bad mouthed a previous employer, co-worker, or client (TheHRSpecialist.com). When asked if there was anything that the respondents did not want a recruiter or employer to see on their profile, $89.6 \%$ of respondents claimed no. When asked to expound upon this question most of the respondents responded they had "nothing to hide", but others stated they had "drunk pictures, or pictures with alcohol and cigarettes" they would not want an employer or recruiter to see. One-tenth of respondents claimed they have posted content that they would not want employers to see, while Harrison's study only yielded $3.1 \%$ of respondents making that claim. Of freshman respondents, $89 \%$ indicated there was nothing they would not want employers or recruiters to see on their social networking profile, while $91 \%$ of graduate students said the same thing. These results have an implication for students who are seeking or will eventually be seeking employment. A study conducted by Careerbuilder.com (2010) revealed that recruiters searching the web for information for a possible job candidate used all possible information portals. Of the resources recruiter/employers used, 29\% used Facebook as a reference, 26\% used LinkedIn, 21\% used Myspace, 11\% searched blogs, and 7\% utilized Twitter (Careerbuilder.com, 2010).

In this study a large majority of respondents $(70 \%)$ claimed to have removed information from their social networking profile they didn't want others to see while only $29.7 \%$ stated they have never removed something from their profile they did not want others to see. The majority of respondents claimed they believed they would not change anything on their profile even if they knew it may be seen by others regardless of the privacy settings on their profile. Only $11.7 \%$ said they would change their profile content if they knew it could be seen.

\section{Do students approve of the fact employers may check their social networking profiles?}

One survey question asked if respondents thought employers and recruiters have the right to check their social networking profile when evaluating whether or not to hire them. The study found that $69.4 \%$ of respondents felt employers or recruiters had the right to check their social networking profile. When the question was crosstabbed with respondent classification, results revealed that $58.4 \%$ of freshman respondents, $70.4 \%$ of sophomore respondents, $81.1 \%$ of junior respondents, $68.1 \%$ of senior respondents, and $80 \%$ of graduate respondents agreed employers and recruiters have the right to check their social networking profile when evaluating whether or not to hire them. When compared to job status, the survey showed that $56.8 \%$ of unemployed, $76.2 \%$ of part-time employed respondents, and $70.7 \%$ of full-time employed respondents agreed employers and recruiters have the right to check an applicant's social networking profile before hiring the applicant. The survey indicated $60 \%$ of respondents seeking employment and $78.8 \%$ of respondents not seeking employment felt employers had the right to check social networking profiles. Respondents were encouraged to explain their answer to the question. These explanations indicated $20 \%$ of the respondents felt employers had the right to view social networking pages because the page is public information that anyone can view. Of the respondents $44 \%$ felt the company had a right to view 
the information in order to learn more about the applicant's personality and to ensure the person is not a liability. The explanations indicated that $30 \%$ of the respondents felt the information was private or that a person's private life is separate from their professional life and employers did not have a right to view the applicants' social networking page.

\section{Are students concerned about the legitimacy of their social networking profile privacy?}

The survey found that $51 \%$ of respondents felt their profile was private, while $49 \%$ felt their profile was not private. Harrisons (2008) study revealed, $43.8 \%$ of respondents felt their MySpace or Facebook profile was private, while $56.3 \%$ did not. When this question was compared between genders the survey indicated males and females had a different opinion on the security of profiles. The findings indicated $60.6 \%$ of female respondents felt that their social networking profile was private, while $61.6 \%$ of male respondents felt that their social networking profile was not private. In a similar study conducted by Hoy and Milne (2010) findings revealed that both men and women were indifferent towards an employer viewing their social networking profile page. The study also indicated that men and women differed in concerns about the privacy of the information posted on Facebook and women respondents were significantly more concerned about the privacy of their social networking profile page than men (Hoy et. al 2010)

\section{Would students give out their social networking profile password in order to be considered for a job?}

The majority of the respondents $(81 \%)$ indicated they were not willing to give out their network profile password to a recruiter in order to qualify for a potential job, while $18.4 \%$ were willing. In the city of Bozeman, Montana a hiring policy was implemented that required applicants to provide their user names and passwords for sites including Facebook, Google, Yahoo YouTube and MySpace. The issue gained national attention when a local television station learned about the regulations from an anonymous viewer. The city manager reported no one was ever denied a job for failing to disclose user names and passwords on password-protected Internet sites and soon after recalled the policy (Business Insurance, 2009). Respondents seeking employment and those not seeking employment demonstrated no significant variance in willingness to give out passwords to be considered for a job. Among the respondents who were seeking employment, $85 \%$ would refuse to reveal passwords to a recruiter for a potential job, while $15 \%$ would reveal their passwords. Of the respondents not currently seeking employment, $81 \%$ would refuse to reveal their passwords and 19\% would agree to do so. Explanations respondents offered against giving their passwords to potential employers included it would be an invasion of privacy. Some respondents said they did not mind if the employer viewed the main profile page because it is available for the public, but giving away the password would be crossing the line. The respondents who would agree to give out their passwords stated they had nothing to hide, they might really need the job, and they could always change their passwords shortly after the employer checks their profiles.

\section{RECOMMENDATIONS}

Further studies may be conducted on employer/ recruiter attitudes and use of social networking websites as a screening tool in order to gain a more well-rounded perspective on the subject. Questions regarding how often this practice is used should be addressed as well as which industries in which it may be most prevalent.

Educational programs may use the results of this and future studies to create informational seminars for students regarding proper social networking etiquette. In particular, career services programs may take more initiative to prepare incoming freshman of the implications of posting inappropriate content on social networking profiles. The need for interview etiquette and social networking etiquette is real. It is recommended that a seminar be conducted for incoming freshman on the implications of inappropriate social networking behavior and its impact on future job prospects. A "Keeping it Clean" campaign may help new students understand the consequences of posting negative content.

Lastly, research may be conducted regarding the ethical implications of employers using social networking websites as a tool of discrimination. Many social networking profiles contain information that is usually illegal to inquire about in a job interview. 


\section{CONCLUSION}

This topic is becoming important as the use of online social networking sites continues to grow. Respondents are aware employers are looking at social networking profiles at the same time many reported there was nothing posted they would not want employers to see. There was also a resounding consensus that respondents were not willing to give out their social networking profile password in order to be considered for a job. These practices may have implications on the future use of social networking websites as the knowledge of recruiters utilizing the sites may incline users to move towards using them for job searching and professional networking.

\section{AUTHOR INFORMATION}

Dalia Elkersh is an MBA candidate who will obtain her degree in December 2010. She wishes to pursue a career in Marketing \& Public relations after graduation.

Jamie Vicknair is an MBA Candidate who will obtain her degree December 2010. She has 3 years of recruiting experience. After graduation she hopes to go into the field of Human Resources.

Katie Yancey is an MBA Candidate with a concentration in Marketing. She will graduate in May 2010 and afterward plans on pursuing a career in the field of Marketing.

\section{REFERENCES}

1. Budden, C.B., Anthony, J. F., Budden, M. C., and Jones, M. A., (2007, $3^{\text {rd }}$ Quarter). Managing The Evolution Of A Revolution: Marketing Implications Of Internet Media Usage Among College Students. College Teaching Methods \& Styles Journal, Vol 3, No. 3: 5-10.

2. Budden, C. B., and Budden, M.C. (2009). The Social Network Generation and Implications for Human Resources. Journal of Business \& Economics Research, Vol.7 No.1: 1-12.

3. Business Insurance News, Analysis \& Articles. (2009, June 29). Password Rule for Job Applicants Gets Backspaced | Business Insurance. 〈http://www.businessinsurance.com/article/20090628/ISSUE0504/306289977>.

4. CareerBuilder.com (2009, August 19). Forty-five Percent of Employers Use Social Networking Sites to Research Job Candidates, CareerBuilder Survey Finds - CareerBuilder. CareerBuilder.com Jobs - The Largest Job Search, Employment \& Careers Site.

$<$ http://www.careerbuilder.com/share/aboutus/pressreleasesdetail.aspx $? i d=p r 519 \& s d=8 / 19 / 2009 \& e d=12 / 31$ $12009 \& \mathrm{cbRecursionCnt}=5 \& \mathrm{cbsid}=500 \mathrm{~d} 5 \mathrm{fc} 2036446 \mathrm{baa} 6 \mathrm{a} 02728 \mathrm{e} 1553 \mathrm{a} 55-323275188-\mathrm{wz}-$ 6\&ns_siteid=ns_us_g_careerbuilder_study_o_>.

5. $\quad$ Facebook.com (2010) "Statistics | Facebook." Welcome to Facebook. 〈http://www.facebook.com/press/info.php?statistics>.

6. Decker, J. (2007). Online Self Reported Information: Facebook a Hiring Tool for Businesses. Thesis. Iowa State University, 2006. Ann Arbor: Proquest Information and Learning Company, 2007.

7. FOXNews.com (2010, February 4). Florida Student Reportedly Kicked Out of Honor Society Over Facebook Page. Breaking News | Latest News | Current News - FOXNews.com. Web. 31 Feb. 2010. $<$ http://www.foxnews.com/us/2010/02/04/florida-student-reportedly-kicked-honor-society-facebookpage/>.

8. Harrison, J. L. (2008). Employer and Recruiter Use of Social Networking Websites as a Candidate Screening Tool. Thesis. Gonzaga University School of Professional Studies, Ann Arbor: ProQuest LLC

9. Hoy, Mariea Grubbs, and George Milne. 2010. Gender Differences In Privacy-Related Measures For Young Adult Facebook Users. Journal of Interactive Advertising 10, no. 2: 28-45. Business Source Complete, EBSCOhost.

10. HR Specialist. (2010, March 30). Heed New Legal Risk of Recruiting via Facebook, LinkedIn Employment Law and Human Resources Solutions. Web. $<$ http://www.thehrspecialist.com/article.aspx?articleid=29918>.

11. Jacobs, P. (2010, February 23). "What Is Social Recruiting?" Business Source Complete. 2-3. Web. 
12. Pew Research Center. (2010). Millennials: A Portrait of Generation Next. Confident, Connected, Open to Change. Rep. Washington D.C.

13. $\quad$ HR Focus. (2009)."Nearly Half of Employers Use Social Media to Research Candidates.": 8-8. Business Source Complete.

<http://ezproxy.selu.edu/login?url=http://search.ebscohost.com/login.aspx?direct=true\&db=bth\&AN=4503 2656\&site=ehost-live $>$.

14. Peluchette, J. and Katherine K. (2008). Social Networking Profiles: An Examination of Student Attitudes Regarding Use and Appropriateness of Content. Cyber Psychology \& Behavior Vol. 11 No.1: 95-97.

Business Source Complete.

15. Oleniczak, M., Pike, C., Mishra, J., and Mishra B. (2010). Employers Use Face Book Too, for Hiring. Advances in Management 3, no. 1: 13-17. Business Source Complete, EBSCOhost. 